\title{
MAPAS DE LA MEMORIA. Un itinerario artístico
}

\author{
Ma Isabel SOLER-RUIZ; Amada MARTÍNEZ-ARENAS \\ Universidad de Granada \\ isasoler@ugr.es, amadamartinezarenas@gmail.com
}

\begin{abstract}
MAPS OF THE MEMORY. An artistical route
Resumen: En el proceso creativo, como en la organización de un viaje, necesitamos explorar, seleccionar y crear. En este artículo comparamos la disposición del individuo ante el paisaje con las del artista que viaja. Este artista-viajero expone su experiencia ante el espectador con un itinerario del mapa de su paisaje mental y con una actitud que coincide con la del romántico atraído por el abismo del viaje, como el que nos presenta Rafael Argullol en su obra "La atracción del abismo", y con el viajero que Mathieu Kessler define en el "El paisaje y su sombra". El acto creativo supone la activación de la conciencia mediante la utilización de la memoria. De igual forma, nosotras, como espectadoras, utilizamos nuestra memoria para interpretar los mapas y entender las claves de determinados artistas y así reconstruir sus paisajes vividos.
\end{abstract}

Abstract: Exploring, selecting and creating are necessary to develop a creative process and a trip plan. This article compares two attitudes: how a person faces a landscape and how an artist faces a journey. The artist-traveller displays his experience through a map which shows an itinerary across his mental landscape. His attitude is similar to the romantic person who is depicted by Rafael Argullol in his essay "La atracción del abismo" and in the same way it is analogous to the traveller defined by Mathieu Kessler in his work "El paisaje y su sombra". Any creative performance activates the conscience by means of memory. In a similar way, we need, as any beholder, our memory to read the maps and to understand the keys of several artists in order to reconstruct their experiences of landscape and journeys.

Palabras clave: Arte Contemporáneo. Mapa Artístico. Artista-Viajero. Memoria. Itinerario Contemporary Art. Artistic Map. Artist-Traveller. Memory. Itinerary 


\section{Introducción}

Todo acto creativo implica, en sus inicios, un viaje al pasado, un recorrido por nuestra memoria. En fases posteriores ordenamos, reorganizamos, reinterpretamos, revisamos y aplicamos los códigos de un lenguaje escogido para que uno o varios interlocutores puedan interpretarlo. Nos centramos, pues, en el artista que necesita de ese viaje para crear; su mapa dibujado será nuestro punto de atención. No sólo nos interesa el mapa de su recorrido, sino también la reconstrucción mental que hace del paisaje visitado. Este paisaje es, a la vez, asumido y experimentado de manera diferente según el tipo de viajero con el que tratemos. Mathieu Kessler define en el El paisaje y su sombra (Kessler, 2000) los términos turista, explorador, aventurero, conquistador y viajero. El artista podría representar cualquiera de estos papeles creando en el paisaje. El artista-viajero unas veces irrumpe en el espacio con sed de conquista, marcándolo para dejar su huella, y otras con respeto y silencio, sin dejar huella de su paso. En cualquiera de los casos es un viaje en solitario, en él se da forma a sí mismo y se establece como un individuo situado en el mundo, abstraído en un punto geográfico, orográfico y cartográfico. Es un individuo consciente de que pertenece a una naturaleza en constante cambio, es un romántico atraído por el abismo del horizonte como el que nos presenta Rafael Argullol en La atracción del abismo (Argullol, 2000) y como el escritor-viajero que nos presenta en su capítulo "El <viaje de viajes>", en Maldita perfección (Argullol, 2013). Argullol escoge aquellos escritores-viajeros que diseñan su viaje mental a priori. En la literatura hemos observado estas mismas actitudes en escritores como Petrarca o Henry David Thoreau. Por otro lado, escogemos artistas como Richard Long, Hamish Fulton, Robert Smithson o Javier Vallhonrat que han buscado inspiración en distintos escritores o aventureros a la hora de viajar y crear y que han necesitado los mismos recursos que el viajero en su proceso creativo: el mapa para la localización geográfica, el registro de lo vivido y el acto de compartir con el otro su experiencia.

Todos estos pasos son necesarios para reconstruir el viaje a posteriori y, a pesar de todo esfuerzo, solo podrá ser compartido en la medida en la que el otro se identifique con el artista-viajero. El recurso de Smithson fue utilizar los términos site / non site, site, para referirse a estar en el sitio, en el punto presente, y nonsite para todos aquellos elementos que, no encontrándose en su contexto original, consiguen transportar o activar la memoria del espectador que viajará mentalmente al lugar. Nuestro recurso es remarcar el término de Alain Roger, in visu, (Roger, 2007:21) para todo acto de contemplación, tanto para los sites como los non-sites, sea la visualización o percepción directa (ver, oír, sentir, percibir) in situ, sea para los signos de ausencia (fotografías, escritos, dibujos, objetos del lugar, grabaciones sonoras...), registros fuera del lugar y del momento presenciado. Estos signos ausentes se nos hacen presentes para reproducir mentalmente el viaje de un otro, pero que ya no mostraremos visualmente; ya solo pertenecerá a nuestra memoria, a nuestro imaginario, algo que no está in visu ("no-in visu", esto es, "non visu").

Trazaremos, pues, nuestro propio recorrido por los paisajes mentales creados por los artistas-viajeros y dibujaremos un mapa conceptual que señale las fases de un viaje y las compare con las fases de la experiencia del proceso creativo.

\section{Mapa}

Nuestro itinerario por el mapa sigue una línea bidireccional que va desde el viaje físico (necesidad de la presencia física) al viaje mental, que requiere un proceso de interiorización de la experiencia, y viceversa [a priori o a posteriori]. Durante el viaje físico nos atenemos a los términos propuestos por Mathieu Kessler (2000: 17-27) para definir las actitudes de un individuo ante el paisaje:

-Turista: espectador pasivo y apresurado por observar lo que recorre sin pararse. No habita ni se siente cambiado por su viaje. No arriesga. No descubre un nuevo itinerario sino que toma uno anteriormente trazado y preparado.

- Explorador: al contrario que el turista, viaja y descubre por sí mismo un itinerario, delimita el espacio y examina lo que le interesa de éste. No se detiene en su viaje, no hay cambio personal.

- Aventurero: se diferencia del turista y el explorador en el hecho de habitar los puntos marcados de su viaje. Tiene un objetivo práctico y arriesga para sorprenderse de lo que puede encontrar a su paso y durante su estancia. 


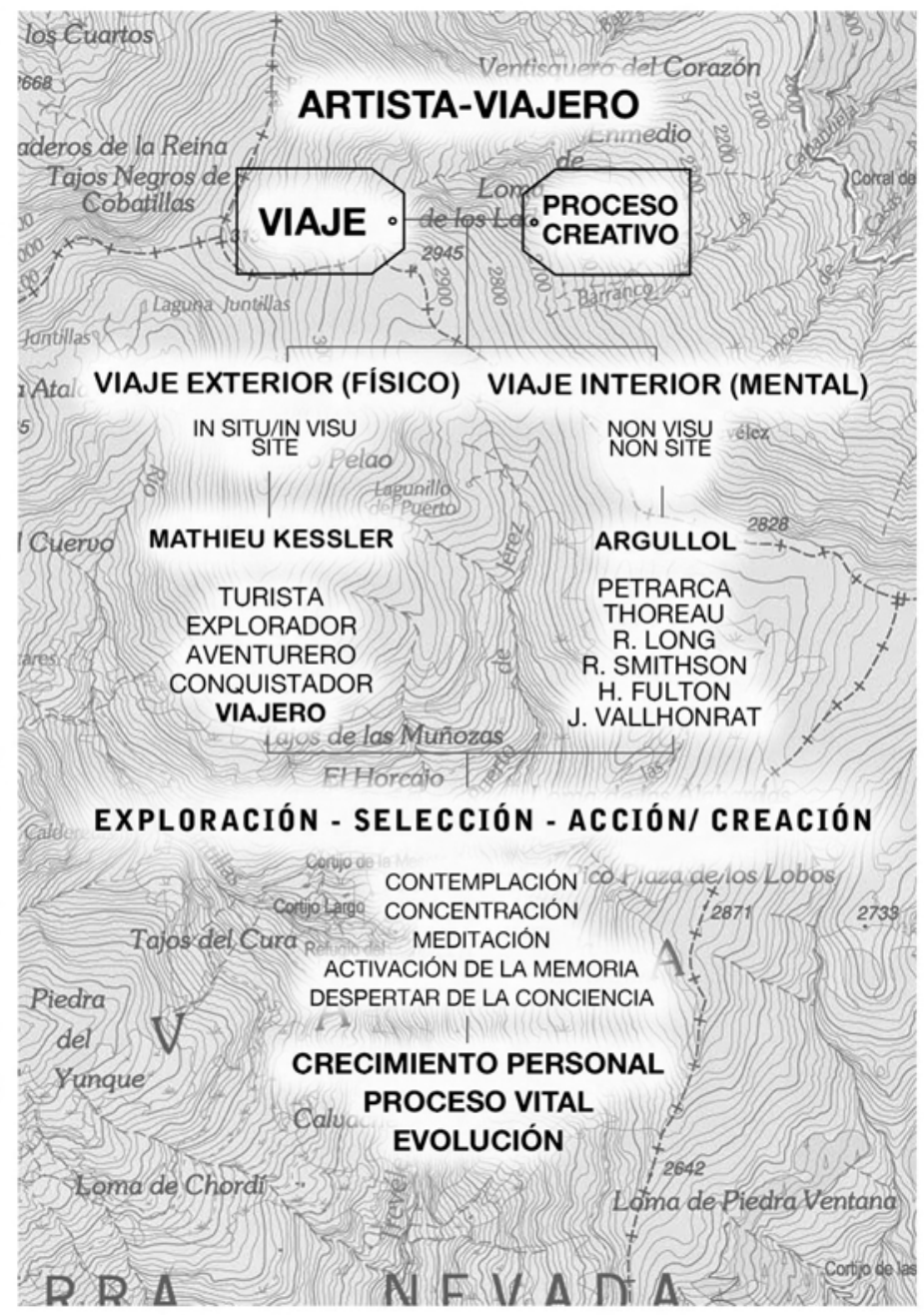

Fig. 1. Mapa conceptual del artículo. Isabel Soler y Amada Martínez. 2013.

- Conquistador: viaja con el objetivo de dirigirse a una localización concreta donde dejar su huella. No da por concluido su viaje si no cambia el paisaje o se apropia de algo que encuentra en el espacio visitado.

- Viajero: olvida el objetivo para dar importancia al itinerario que él mismo traza. Su ruta está marcada por la duración y el espacio, medita, experimenta y descubre para sí mismo. El viajero vive y se implica, activa su memoria y toma conciencia de su relación íntima y corporal con el espacio recorrido para interiorizar e interpretar lo vivido. Cada viaje queda marcado en su memoria y le produce un cambio personal.

Podemos afirmar que en cualquier caso ante el paisaje siempre se produce un cambio en el individuo, sea en mayor o menor grado, y en todos se produce un proceso de interiorización. En muchos casos es vivido como un rito iniciático que necesita de una preparación previa y un encuentro consigo mismo ante una nueva vivencia: "un aprendizaje, una prueba, un conocimiento" (Argullol, 2013: 132).

En este proceso observamos tres fases fundamentales: exploración, selección, acción. Una vez decidido el lugar se explora a priori en mapas y documentos, se selecciona o marcan los objetivos, se traza el recorrido y se actúa, comienza el viaje y con él, de nuevo, los mismos procesos de exploración-selecciónacción. La exploración y la selección incluirían estados de contemplación, concentración y meditación, y las acciones darían lugar a apuntes, fotos, dibujos..., signos del acto creativo, de tal manera que el último estado sería el despertar de la conciencia.

En un proceso de creación se producen las mismas fases, exploración-selección-acción, y los mismos estados: 


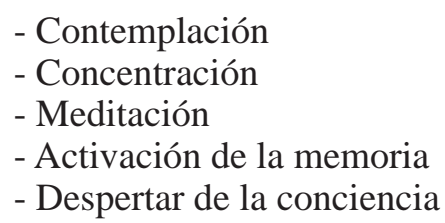

Por tanto, el resultado de la experiencia del acto creativo y del acto de viajar conduce a un crecimiento personal, un desarrollo y proceso vital y una evolución.

\section{Itinerarios artísticos}

Una meditación silenciosa y enriquecedora y una interiorización de la experiencia del acto de creación y del viaje consiguen que el viajero de Kessler y el romántico de Argullol confluyan en una misma figura. Robert Smithson y Henry David Thoreau sirven de ejemplo del "romántico que viaja hacia fuera para viajar hacia dentro y al final de la larga travesía, encontrarse a sí mismo" (Argullol, 2000: 86). En el caso del cuaderno de viaje publicado en Artforum en 1969, "Incidentes del viaje-espejo en el Yucatán" (Smithson, 1969), R. Smithson toma el papel de artista-viajero y consigue que ambos viajes, físico y mental, estén estrechamente ligados. Esto lo demuestra a través de la dialéctica entre sus itinerarios físicos (site) y su consecuente interiorización: una travesía mental (non visu) que nos revela como non site (aunque puedan contemplarse como in visu). La experiencia real marcada por un itinerario y las paradas concretas dan forma a su mapa cartográfico y a sí mismo (Soler, 2001: 45-51). Se modela constantemente como individuo cartográfico: "La mente de uno y la tierra están en un estado de erosión constante, los ríos mentales desgastan riberas abstractas, las ondas cerebrales socavan acantilados de pensamientos y las cristalizaciones conceptuales se separan formando depósitos de razón arenosa" (Enguita, 1993: 125). Cada itinerario y cada parada lo van modelando, erosionando, y quedan marcados en su mapa personal. Este mapa es fruto del estado de concentración y meditación de R. Smithson para acercarse al paisaje. A posteriori, cada huella queda expuesta como vía de exteriorización de su experiencia para activar la memoria del espectador, un lector-espectador que reconstruirá un viaje mental basándose en su propia experiencia. Este lector-espectador debe revivir este viaje mental pasando por los mismos estados, desde la contemplación directa deberá
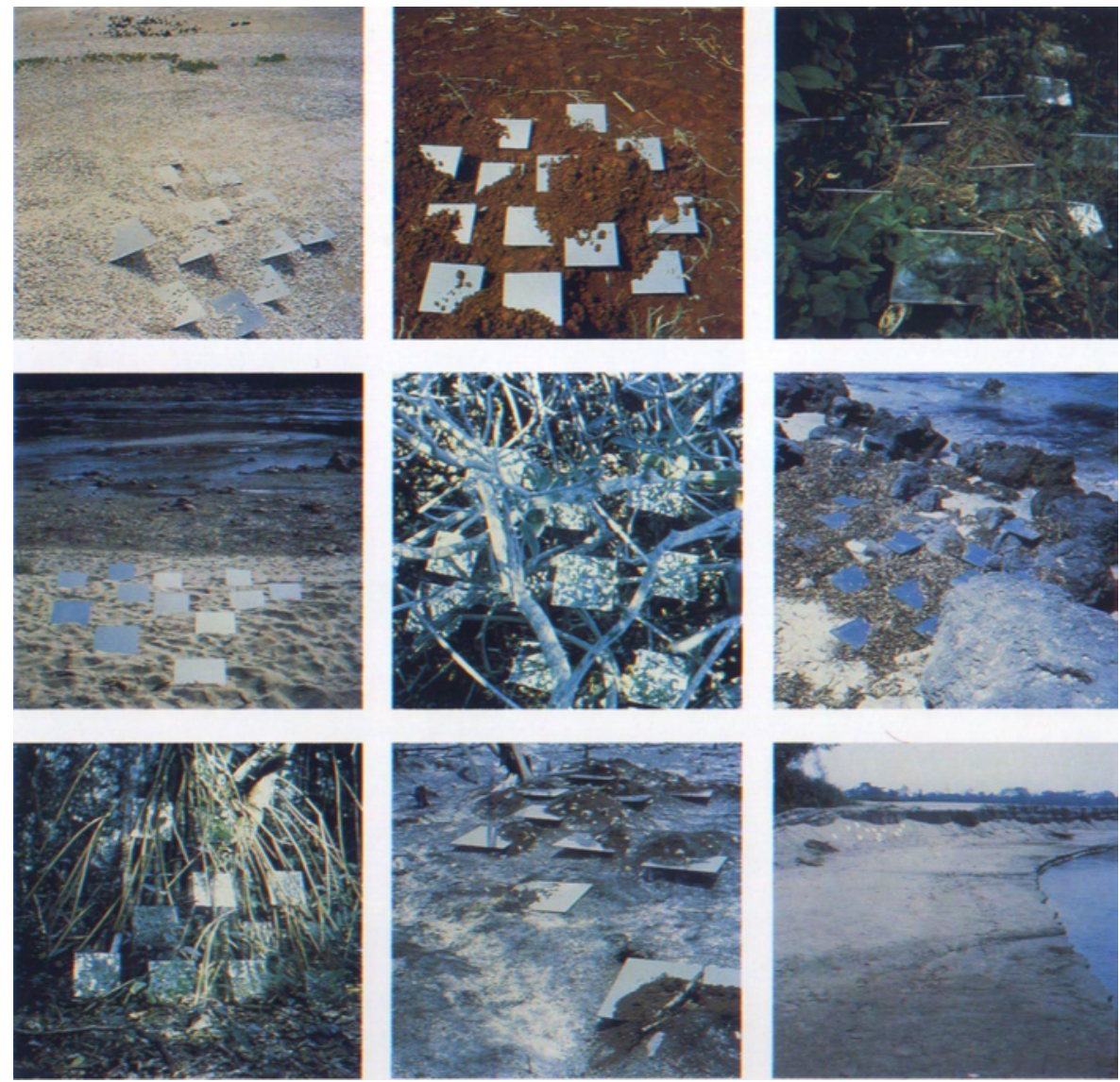

Fig. 2. Robert Smithson. Yucatan mirror displacements, 1969. Yucatán. México. 
mantenerse concentrado en las claves mostradas para lograr, mediante su propia meditación, activar su memoria para adentrarse en la de Smithson y completar así el viaje. "El modo de ver del artista (y espectador) es un proceso doble [...] experimentar una modalidad de consciencia ligeramente alterada; en segundo lugar, ver las cosas de un modo diferente" (Edwards, 2003). El viaje que realiza el artista-viajero y el lectorespectador-viajero son coincidentes en el proceso mental que sucede en el acto creativo, ambos alcanzan una mística activación de la mente y captan lo que normalmente podría pasar desapercibido (Edwards, 2003) : Smithson se acerca a contemplar Yucatán en un estado de concentración que le permite captar detalles que culminan en la activación de su conciencia, una conciencia que exterioriza en su cuaderno de viaje "Incidentes del viaje-espejo en el Yucatán" o en su acción realizada en cada "desplazamiento de espejos". Entonces, cuando el espectador lee y contempla las imágenes del artículo de R. Smithson (Smithson, 1969) viaja mentalmente (non visu) hasta Yucatán intentando con su identificación reconstruir su experiencia in situ (in visu). Debe meditar ante lo contemplado para activar las claves mostradas y llegar así al final de su propio viaje. Aunque su huella no sea perenne, podemos ser testigos in visu de esta conquista contemplando las fotografías de los espejos en cada emplazamiento (Soler, 2003: 122-136), observamos cómo toma el mapa de Yucatán que cualquier turista utilizaría para conocer previamente itinerarios y marcar localizaciones claves para él. Cada parada es un acto de creación, traspasa el lugar y lo llena de percepciones y emociones que nos transmite en su relato.

De igual forma, H. D. Thoreau, como escritor-viajero, traza su propio itinerario para convertir cada una de sus experiencias vitales en la base de sus obras creativas. Hallarse in situ en el bosque era para Thoreau su propio estado de concentración, meditación y una verdadera forma de arte, y caminar significaba dirigirse física y espiritualmente hacia los lugares que recorre (Thoreau, 1977). Habita y se implica con cada trayecto o lugar y sólo su memoria es el medio para transmitir sus vivencias creando non sites como Smithson. Ambos rescatan de su memoria sus experiencias, ambos admiten que cada camino trazado modifica su mapa personal y lo demuestran creativamente:

"Estamos obligados a vivir concienzuda y sinceramente, reverenciando nuestra vida y negando la posibilidad de cambio. Decimos que este es el único camino; pero hay tantos caminos como radios pueden trazarse desde un centro. Cualquier cambio es un milagro digno de ser contemplado" (Thoreau, 1999: 11-12).

Thoreau decide escapar hacia el bosque convirtiendo este trayecto en su propio viaje interior, en un trazado alternativo del camino impuesto guiado por el "estímulo del que desea conocer, descubrir, indagar y ampliar sus horizontes para cambiar su mirada hacia el hombre y el mundo al que pertenece" (Soler, 2003: 50). La actitud de Henry David Thoreau demuestra que el punto de partida es el centro de uno mismo y desde él trazamos nuestros itinerarios. El objetivo principal en cada trazado es vivir la experiencia de forma creativa y consciente.

El paralelismo mental que subsiste bajo los términos non visu y non site conforma el viaje que Rafael Argullol plantea como "mirada interior" (Argullol, 2000: 86): una visión indirecta de lo experimentado. Para posicionarse como espectador ante los signos de un non site es necesario comprender que se trata de "contemplar lo contemplado" (Argullol, 2000: 63-73), activar la imaginación para explorar en nuestra memoria y realizar nuestro propio viaje mental como abstracción del viaje físico realizado por otro. Es un proceso constante entre lo experimentado y lo proyectado. Ahora lo percibido es lo que se extrae de un itinerario que ya se ha interiorizado y moldeado por la experiencia previa del espectador-viajero. Los paisajes vividos se modifican con el paso del tiempo y con los cambios que se producen en nuestra memoria y estos nuevos paisajes volverán a ser interiorizados por cada persona en un proceso exterior-interior constante.

Richard Long viaja en 1994 para realizar A circle in Huesca, y su desplazamiento es más importante que cualquier conquista que realiza in situ valiéndose siempre de elementos del lugar. Recorre el Pirineo Aragonés y traza una ruta que asciende al macizo de la Maladeta para dejar su hito a más de 2.000 metros de altitud. Otorga especial importancia al trayecto, pues para acceder a su huella, es imprescindible seguir sus pasos concienzudamente para experimentar una dura ascensión en zigzag que casi alcanza la cumbre.

La ascensión de Richard Long a la Maladeta puede compararse con la ascensión de Petrarca al Monte Ventoso en 1336. A cada paso ganaban conciencia del tiempo y el espacio, conciencia sobre su cuerpo en movimiento, un cuerpo geográfico situado en una latitud y longitud determinada. Ambos se sienten como el viajero que Kessler relaciona con la montaña: "Toda montaña inscribe su huella en un espacio geográfico temporalizado, vivido, constantemente contemplado y rememorado" (Kessler, 2000: 24). Rememoran su experiencia, tiempo, espacio, imágenes y sensaciones y hacen visible su huella en el trayecto a través de fotografías y documentos que R. Long archiva y muestra, o escritos que Petrarca narra dictados por la conciencia de ese sentido profundo del ser que se adquiere en la ascensión a una montaña (Torrás, 2000). 

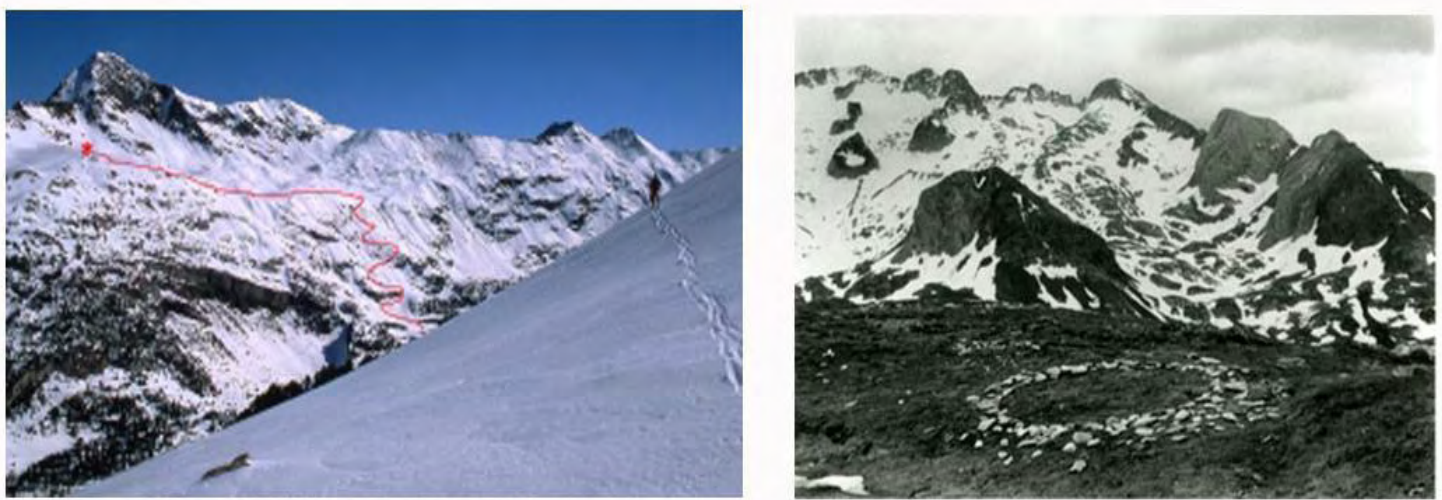

Fig. 2. Richard Long. A circle in Huesca, 1994. Fotografía y recorrido realizado por R. Long. Macizo de la Maladeta. Huesca.

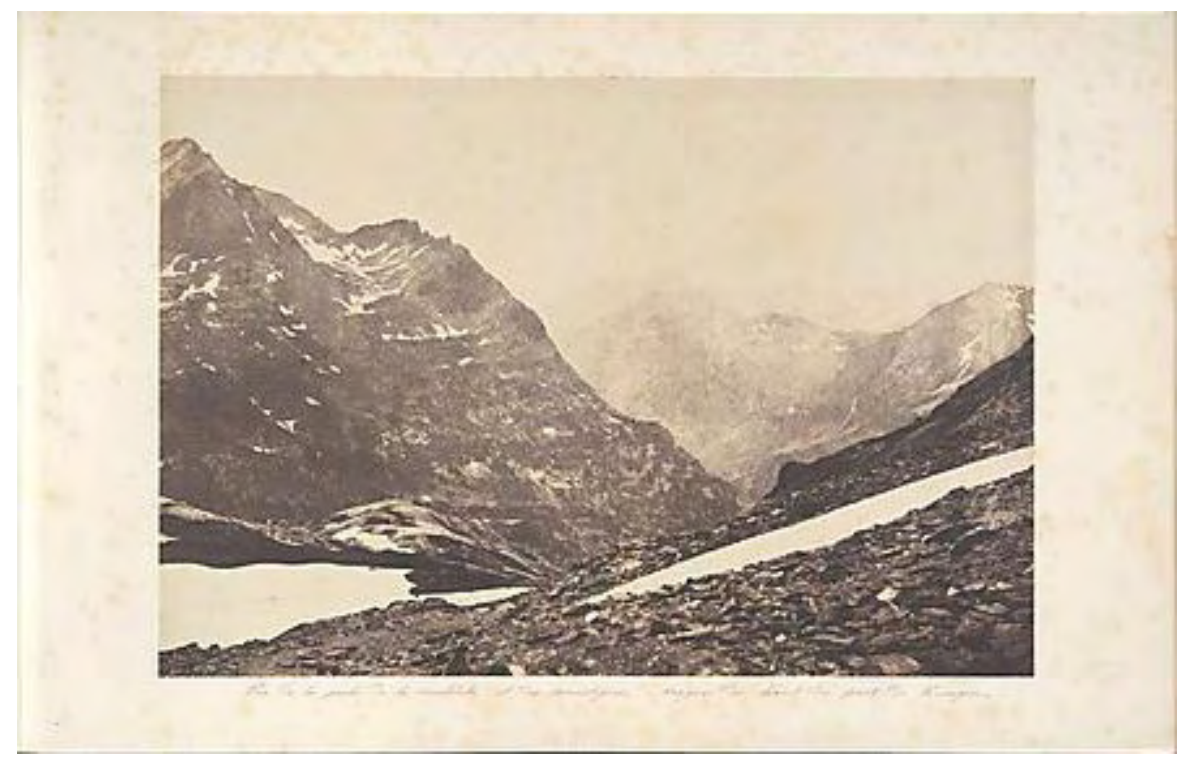

Fig. 4. Joseph Vigier. Album des Pyrénées, 1853. Macizo de la Maladeta. Huesca

Javier Vallhonrat interioriza el viaje del fotógrafo Joseph Vigier a los Pirineos en 1853, en concreto también al macizo de la Maladeta, para llevar a cabo su propio viaje. Contempla lo contemplado por Vigier partiendo de sus imágenes tomadas 159 años antes. En su proyecto $42^{\circ} \mathrm{N}$ de 2012 realizó 19 ascensos a este macizo que presenta en un mapa creativo ${ }^{1}$. Según Vallhonrat las imágenes de Vigier son fragmentos extraídos de la realidad y es necesario activar la memoria para recrear o rememorar un espacio que solo puede ser comprendido y contemplado en su totalidad a través de la experiencia. De esta forma, socava y busca en la memoria de Vigier, para recrear en la suya dicha experiencia y planear así su propio viaje. Cuando lo realiza es cuando realmente penetra en la memoria de Vigier para obtener una experiencia cercana a la suya. Vallhonrat se ha posicionado, en primer lugar, como espectador para conformar en su memoria lo que le sirve de punto de partida para trazar de nuevo sobre el mapa el recorrido por los Pirineos; parte ahora de su propia memoria y actúa como creador. Explora la memoria de Vigier, selecciona entre sus imágenes y crea a partir de ellas. Para Vallhonrat la vivencia con el paisaje in situ es la recompensa principal que extrae de

\footnotetext{
1 Este proyecto es uno de los cinco bloques temáticos que pertenecen a Interacciones (2011-2015), proyecto completo que estuvo expuesto en el Centro Galego de Arte Contemporánea de Santiago de Compostela del 29 de octubre de 2015 al 20 de marzo de 2016 (http://cgac.xunta.gal/ES/exposicion-detalle/59/JAVIER-VALLHONRAT.-INTERACCIONES\#ad-image-0) y en el Museo Universidad de Navarra (13 mayo 2015) (https://elpais.com/cultura/2015/05/13/actualidad/1431529606_636771.html). Interacciones lo completan cuatro bloques más: "Deriva estándar", "Fricción límite", "Registros del margen” y "Eolinimia" (2013-2015) donde Kåre Aarset, meteorólogo y poeta escandinavo de ficción o alter ego, muestra la fragilidad humana ante lo inconmensurable de la montaña, proyecto que también se expuso en la galería aural en Alicante del 13 de junio al 31 de octubre de 2015. (http://www. auralgaleria.com/javier-vallhonrat-eolionimia/). La información completa sobre los conceptos e imágenes de esta obra pueden verse en la página web personal del artista: http://www.javiervallhonrat.com/art/
} 
sus actos creativos, transgrede los "límites de una reflexión puramente artística" (Kessler, 2000: 31) para desarrollarse creativamente a través de lo que realmente le motiva: la experiencia vital con el paisaje. Esta motivación es el origen de sus proyectos. Se aventura y vive el paisaje partiendo de éste para ser un intérprete de las experiencias que le proporciona experimentar la montaña, pues según M. Kessler el viajero es un "intérprete" que "compone y edifica su pensamiento en torno al espacio geográfico tal y como este se presenta, para operar en una síntesis original, personal, inimitable [...]" (Kessler, 2000: 36). Para Vallhonrat, tras la contemplación, esa síntesis se consigue mediante el silencio que permite escuchar al propio cuerpo, una meditación que hace visible en su proyecto " $42^{\circ}$ N" (Vallhonrat, 2012). Todo viaje implica así un recorrido por diferentes estados subjetivos en consonancia con la altitud, la climatología y toda una serie de elementos en constante cambio que afectan a la percepción y los sentidos dejando una huella interna en la memoria. En sus proyectos consigue otro tipo de conquista: la recompensa que le proporciona la experiencia in situ. No deja huella de su viaje en el paisaje pero lo refleja con el mapa, (fig. 5) con la transmisión de la vivencia en sus palabras y con las fotografías de reconstrucciones de su paisaje mental; el conjunto permanece como fragmentos de una pieza global que el espectador-viajero debe reconstruir de nuevo, un nuevo paisaje que localice en su propio mapa mental. Él mismo describe $42^{\circ} \mathrm{N}$ como "una serie de recorridos, de viajes externos, en los que las imágenes son huellas, pequeños fragmentos, que van dibujando una metáfora de un recorrido interno" (Vallhonrat, 2012). Evidencia aquí el viaje exterior e interior que ligamos al proceso creativo. Un ejemplo más del individuo cartográfico que va sumando recorridos a su vida y, por tanto, a su trabajo creativo.

Con Hamish Fulton conectamos de nuevo con Thoureau. Para ambos, caminar es una forma de arte, son caminantes (Thoreau, 1977) que van modelándose en su caminar y las vivencias que encuentran se graban en su rostro, en su memoria vital, (Soler, 2003, p,173) en aquella donde las vivencias no tienen que ser rescatadas del recuerdo para activarlas, sino que se encuentran activas permanentemente porque han sido integradas en su subconsciente, han sido grabadas en su persona profundamente y se verán reflejadas más tarde en lo que recrean de forma plástica, uno, y literaria, el otro. H. Fulton añade recorridos a su mapa, pero no deja huella de su paso. Desde 1979 hasta 2008 realizó diversas caminatas de costa a costa por la Península Ibérica (Fulton, 2008). Explora la Península tomando el mapa donde traza y selecciona previamente sus trayectos, actúa recorriéndolos y anotando la fecha y tiempo empleado en su viaje: "de un minuto hasta 59 días de duración, 1979-2008" (Fulton, 2008). Su recuerdo es su principal cuaderno de su viaje, extrae fotografías y conceptos de cada ruta y los plasma y archiva en una publicación que se convierte en el mapa de sus trayectos en un mapa conceptual extraído de su mente. Podemos viajar su viaje in visu de página en página, pasando por carreteras y ascendiendo a montañas como el Mulhacén, cruzando desde Ribadesella hasta Málaga, desde la costa de Portugal hasta Alicante. De cualquier forma, su viaje proyecta lo experi-

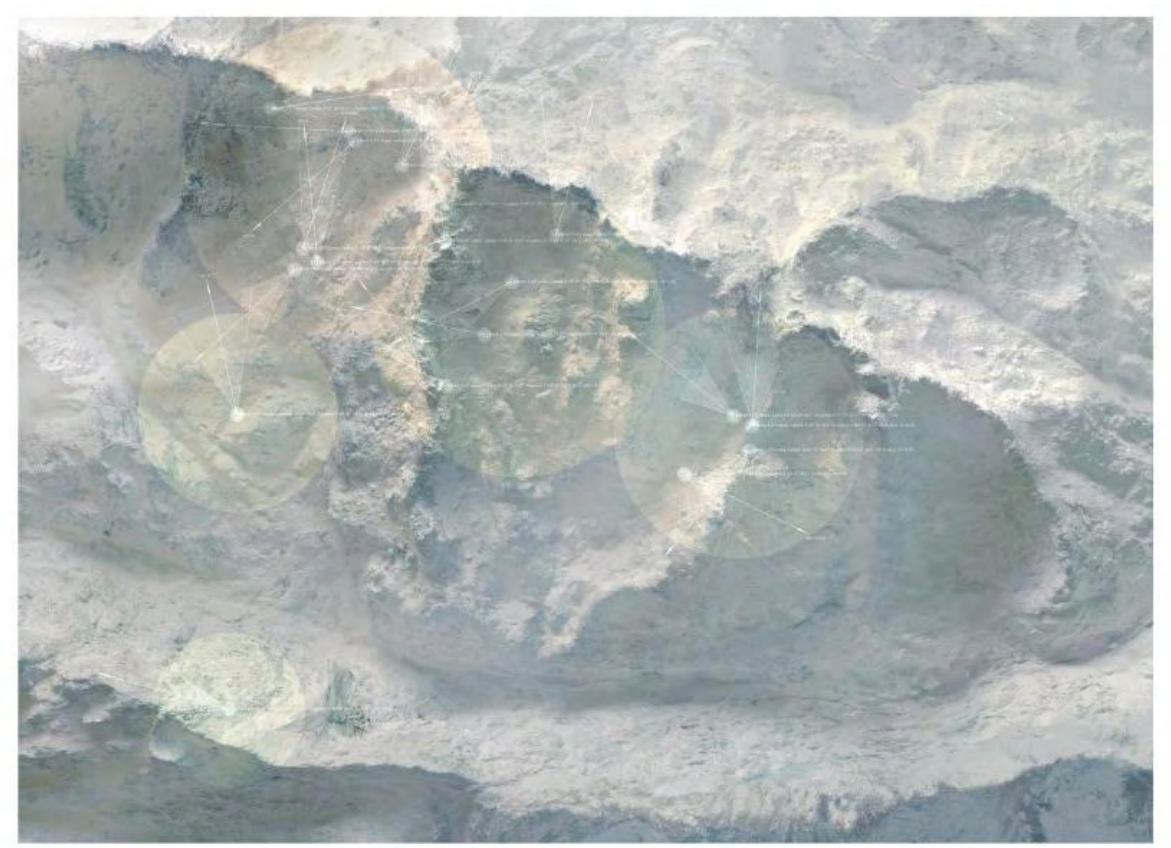

Fig. 5. Javier Vallhonrat. Mapa de $42^{\circ} \mathrm{N}, \mathbf{2 0 1 2}$, donde se marcan los recorridos y localizaciones para la toma de las fotografías. Macizo de la Maladeta, Huesca. 


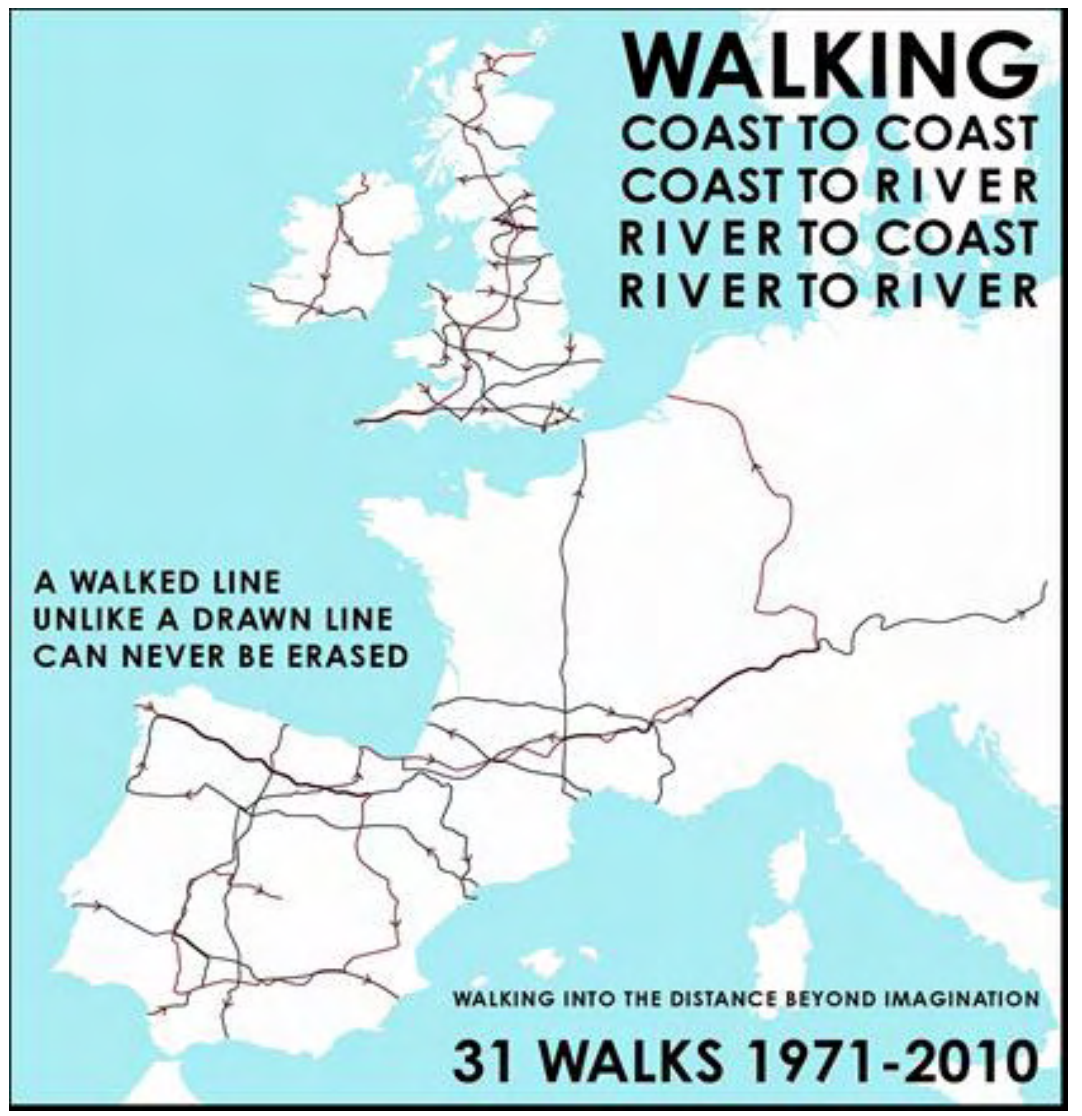

Fig. 6. Hamish Fulton. Mapa de recorridos por la península Ibérica. 1971-2010.

mentado, las suelas de sus zapatillas son una metáfora del recorrido realizado y la experiencia adquirida. Se convierten en un paisaje erosionado, en un mapa emborronado, son el reflejo de un compromiso físico repleto de metas personales cumplidas. Toma su mapa como un diario y refleja sus líneas de salida, los puntos de sus llegadas que se unen en un trayecto infinito.

De manera similar, Eduardo Nave y Juan Millás recorren la Península y marcan las latitudes de cada imagen registrada. La publicación resultante vuelve a construirse con un mapa mental de fotografías y textos sobre tres de ellas, que son elegidas por Rafael Argullol, Alejandro Castellote y Estrella de Diego para dar la visión del espectador que revive un instante del viaje. De nuevo el espectador viaja in visu en la forma en la que los autores invitan a verlo, del mismo modo como ellos vivieron su viaje, saltando de un lugar a otro en una deriva intermitente que plantearon como su método de viaje como un "extravío intencionado" (Nave y Millás, 2013).

Otra forma de interiorizar un viaje realizado por otros viajeros es el de "Moldura" de Perejaume. Reconstruye en su memoria el viaje de los buscadores de oro y nos sirve de ejemplo del conquistador que nos definía Kessler. En este mismo papel, como un artista que "se abre paso por el espacio geográfico [...] lo cambia y lo transforma" (Kessler, 2000: 20), interviene con pan de oro en un nevero de Sierra Nevada, en la Loma Papeles cerca de Güéjar Sierra. En este caso, importa más el punto que se conquista que el recorrido, la orografía y la localización puntual, que el camino para llegar a él. El elemento "Moldura", que se repite varias veces en su trabajo, actúa como el marco para contemplar la porción de paisaje que ha escogido, como un fotograma extraído de su memoria. Indica dónde quiere que detengamos nuestro paso y nuestra mirada para constatar el mismo estado de contemplación y meditación que él ha vivido anteriormente durante su acto creativo.

El viaje también es el medio de creación de Olafur Eliasson. Sirve como ejemplo de exploración, selección y acción pues él mismo afirma que "hace un plan de viaje y camina hasta encontrar lo que necesita" (Martínez de Corral, 2006: 45) así pues lo que le interesa es recorrerlo y sentirse formando parte del paisaje que fotografía. Sus viajes a Islandia son un viaje físico que le devuelve a su origen, a su memoria personal, al lugar que ha despertado su creatividad durante años, Islandia es su lugar de meditación. Allí realiza su recorrido y nos propone una aproximación de su viaje al paisaje para que nos sintamos parte de él, "es nuestro territorio, el producto de nuestra vida, nuestros viajes y nuestro imaginario [...] actuando como un activador de la memoria, de la experiencia y del espacio" (Martínez de Corral, 2006: 45). 
Como Vallhonrat, selecciona porciones del paisaje recorrido para construir el viaje que nos propone. Con las fotografías archiva y registra su viaje que ofrece a través de su personal visión como podemos ver en Path of Nature (Caminos de Naturaleza), donde las secuencias de imágenes tienen por objetivo evidenciar un recorrido y transmitir el paisaje vivido como una experiencia temporal.

Como Smithson, se siente identificado con la orografía del terreno, con los accidentes geográficos como glaciares, fallas o ríos y con aquellos espacios que en los que se evidencia la actividad e intervención humana. Para Eliasson la relación con los lugares tiene un carácter cultural, afectivo, que habla de nuestra propia naturaleza y origen.

\section{Derivaciones}

Cada viaje ofrece al que lo experimenta multitud de itinerarios a elegir. Hasta aquí hemos elegido un itinerario a través de obras de artistas-viajeros con los que nos identificamos. Como puntos de conexión encontramos la pasión por la vivencia del paisaje, la idea de viaje y el uso de la memoria para la reconstrucción personal del viaje. Situándonos tanto en el papel de creadoras como en el de espectadoras, hacemos un recorrido del recorrido, o como bien dice Argullol, una contemplación de la contemplación. Con todos los sentidos atravesamos el mapa que se extiende a nuestros pies, trazamos en él nuestras huellas y recuerdos o leemos pistas que quedan sobre el mapa del viaje de otro.

Conscientes de que no podemos vivir lo que estos artistas-viajeros experimentaron, hemos establecido un proceso de identificación con sus posibles motivaciones, con sus paisajes de inspiración y con sus actos creativos.

Las actitudes del viajero definido por Kessler y las actitudes del artista definidas por Argullol nos han marcado este itinerario artístico. Los puntos en común de sus viajes son la concentración, contemplación, meditación, memoria y conciencia que dan lugar al cambio personal, al proceso iniciático y al encuentro con uno mismo. En todos ellos, la acción del viaje, la percepción del paisaje y la emoción que genera son el origen creativo, la fuente de inspiración. Estos viajeros parten con un recorrido directo hacia el centro de crecimiento personal, la fuente de donde nace de forma innata la creatividad.

La memoria ha demostrado ser un punto imprescindible del itinerario planteado. El tipo de memoria que poseen estos artistas-viajeros va más allá del hecho de recordar, es una memoria integrada en su ser y forma parte de ellos mismos. Más allá de los elementos rescatados y seleccionados para guiar al espectadorviajero por su trayecto, éste ha sido grabado y existe en sí mismo como elemento fundamental de su mapa interior, del mapa de su vida. La toma de conciencia del cambio producido interiormente es la que da lugar al desarrollo, conocimiento y crecimiento personal.

Tanto el proceso de interiorización de un viaje como el proceso de un acto creativo conllevan una exploración, una elección y un acto de creación: cada acto creativo es un camino más en un entramado de rutas que avanzan y confluyen, cada camino de este viaje es como un rastro grabado que socava en la memoria y activa el recuerdo vivo de la experiencia.

Todas estas palabras se reescriben siguiendo el mismo patrón del proceso creativo del artista-viajero: marcar los lugares de exploración, unir los puntos para trazar el itinerario, explorar los territorios y, con respeto, dejar una huella tras un proceso de interiorización y creación.

\section{Bibliografía}

Argullol, R. (2000). La atracción del abismo. Barcelona: Destino.

Argullol, R. (2013). Maldita perfección. Escritos sobre el sacrificio y la celebración de la belleza. Barcelona: Acantilado.

Edwards, B. (2003). Nuevo aprender a dibujar con el lado derecho del cerebro : libro de trabajo : ejercicios guiados en las Cinco Técnicas Básicas del Dibujo. Barcelona: Urano.

Castro, X. A. (2004). Illa das esculturas. Pontevedra: Diputación Provincial de Pontevedra.

Enguita, N. (Coord) (1993). Robert Smithson. El Paisaje Entrópico (Textos: M. Gilchrist / J. Lingwood y Kay Larson. Traducción: Harry Smith). I.V.A.M. Centre Julio González, 22 Abr /13 Jun, 1993, Valencia: Institut Valencià d'Art Modern.

Figueroa, V. (2015). "Javier Vallhonrat y el frío de la incertidumbre". Recuperado 07 de septiembre de 2017. https://elpais.com/cultura/2015/05/13/actualidad/1431529606_636771.html

Fulton, H. (2008). El camino: Rutas por la península ibérica. Badajoz: Fundación Ortega Muñoz.

Hontoria, J. (2013). “Olafur Eliasson”. El Cultural, 2006. Recuperado 18 de Diciembre de 2013, de http:// www.elcultural.es/version_papel/ARTE/17404/Olafur_Eliasson/

Kessler, M. (2000). El paisaje y su sombra. Barcelona: Idea Books. D. L. 
Long, R. (2007). Walking and marking. Edinburgh: National Galleries of Scotland, cop.

Long, R. (1997) From time to time. Ostfildern: Cantz.

Maderuelo, J. (dir. ). (2007). Paisaje y arte. Madrid: Abada.

Maderuelo, J. (dir. ). (2008). Paisaje y territorio. Madrid: Abada.

Martínez de Corral, L. (comis.). (2006). “Olafur Eliasson: Caminos de Naturaleza”. Madrid: Fundación Telefónica / La Fábrica.

Nave, E. y Millás, J. (2013). Península. Madrid: PHREE.

Smithson, R. (1993). Una sedimentación de la mente: proyectos de tierra, en Robert Smithson, IVAM. Valencia: Centre Julio González.

Reynolds, A. M. (2003). Robert Smithson: Learning from New Jersey and elsewhere. Cambridge: MIT Press.

Roger, A. (2007). Breve tratado del paisaje. Edición de Javier Maderuelo. Madrid: Biblioteca Nueva.

Rosenthal, M. (2003). Understanding installation art: from Duchamp to Holzer. Munich: Prestel.

Soler Ruiz, M. I. (2003). Reflexiones en el espacio: Incidents of mirror-travel in the Yucatan, Robert Smithson. Granada: Facultad de Bellas Artes, Universidad de Granada.

Smithson, R. (1969). "Incidents of Mirror-Travel in the Yucatan". Artforum, Sept, 1969. New York, 1969. ISSN: 0004-3532, 28-33.

Thoreau, H. D. (2004). Caminar. Barcelona: El Cid Editor.

Thoreau, H. D. (1999) Walden. La vida en los bosques. Buenos Aires: Errepar.

Torrás, M. (2000). Manifiestos del humanismo: Petrarca, Bruni, Pico della Mirandola, Alberti. Barcelona: Península.

Vallhonrat, J. (2012). -“42N: Una nueva mirada al itinerario fotografiado por Vigier 150 años”. Pamplona: Museo Universidad de Navarra, 2012. Recuperado 21 de Noviembre de 2013, de www.unav.es/ museo/javier-vallhonrat/42on/

Vallhonrat, J. (2015). "Interacciones (2013-2015)". Recuperado 07 de septiembre de 2017 de http://www. javiervallhonrat.com/art/

Vallhonrat, J. (2015). "Interacciones (2013-2015)". Recuperado 07 de septiembre de 2017 dehttp://cgac. xunta.gal/ES/exposicion-detalle/59/JAVIER-VALLHONRAT.-INTERACCIONES\#ad-image-0/

Vallhonrat, J. (2015). “Eolionimia (2013-2015)”. Recuperado 07 de septiembre de 2017 dehttp://www. auralgaleria.com/javier-vallhonrat-eolionimia/ 